ISSN1027-5495. Functional Materials, 23, No.4 (2016), p. 624-629

doi:https://doi.org/10.15407/fm23.04.624

(C) 2016 - STC “Institute for Single Crystals"

\title{
The following performance between particle and fluid medium inside hydrocyclone with double vortex finders
}

\author{
Yuekan Zhang, Junru Yang, Peikun Liu, Xinghua Yang \\ College of Mechanical \& Electronic Engineering Shandong University of Science \\ and Technology, Qingdao, 266590, R.P. China
}

Received September 23,2016

\begin{abstract}
In this paper, we used numerical simulations to study the effect of size, density and concentration of particles on the relative motion between two phases in a cyclone separator with double vortex finders, which is different than a traditional separator that has only one overflow pipe. Keywords: following performance; numerical simulation; hydrocyclone with double vortex finders

В данной работе использованы результаты численного моделирования для изучения влияния размера, плотности и концентрации частиц от относительного движения между двумя фразами в циклонном сепараторе с двойными вихревыми искателями, который отличается от традиционного сепаратора, имеющего только одну перепускную трубу.

Дослідження взаємозв'язку між часткою і текучим середовищем всередині гидроциклона $з$ подвійними вихровими шукачами. Юкан Чжан, Джунрі Ян, Пейкун Лiу, Синхуа Ян

У даній роботі використані результати чисельного моделювання для вивчення впливу розміру, щільності і концентрації частинок від відносного руху між двома фразами в циклон сепараторі з подвійними вихровими шукачами, який відрізняється від традиційного сепаратора, що має тільки одну перепускну трубу.
\end{abstract}

\section{Introduction}

In a hydrocyclone separator, the solid particles in a liquid medium are subject to centrifugal force, buoyant force towards the center and dragging force from the liquid medium[14]. The larger the particle size, the bigger the centrifugal force and the circling radius. So the larger particles usually enter into the underflow, while the smaller particles are transferred to the overflow. Currently, most theories for the separating process is based on the mathematical treatment of different particle sizes, which include the balanced orbit theory[5-6], the stay time theory[7-8], the block and discharge theory[9] and the turbulence theory of two phases[10]. Most of these theories are qualita- tive. By analyzing the following performance between the particles and the liquid medium, this paper is intended to give a quantitative analysis of the flow characteristics in the cyclone separator

For a cyclone separator, the motion of particles is mainly determined by the particle size, density and concentration difference between the solid particles and the liquid medium. Under the centrifugal force, the particles move from the center to the wall and sediment there and therefore the particles are separated from the liquid medium. In other words, the reason that the particles are able to be separated from the liquid medium is because there is a sliding speed difference between them in the radial direction, which is called the following perfor- 

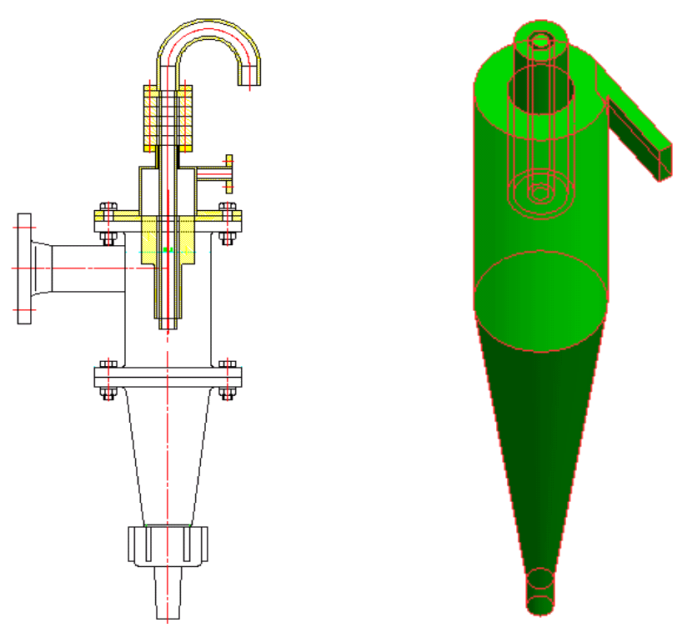

Fig. 1 Structure diagram of the hydrocyclone with double vortex finders

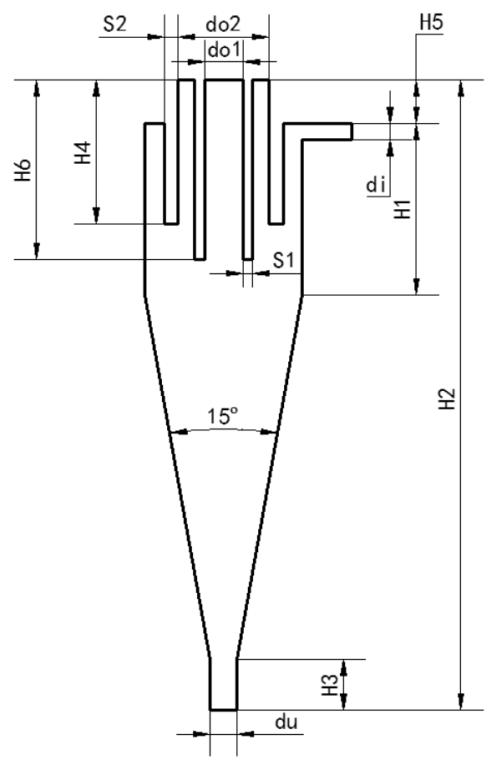

Fig. 2 Flow field of cyclone with double vortex finders

mance between the particles and the liquid medium. Furthermore, the larger the difference of the speed, the easier the separating process. In reverse, the smaller the difference, the harder the separating process. As a result, it is crucial to study the relative motion between the particles and the liquid medium in order to determine the optimal parameters in separating them from each other. In this paper, we will use numerical simulations to investigate the factors that affect the relative motion between the particles and the liquid medium in tangent, radial and axial directions.
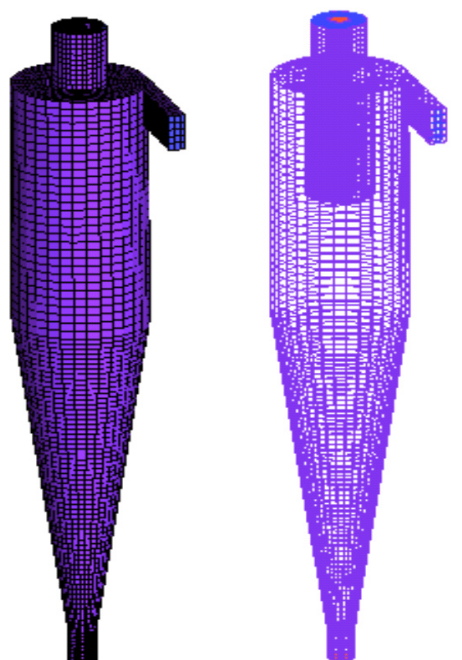

Fig. 3 Meshes of the hydrocyclone

Table 1 Main structural parameters of the hydrocyclone with double vortex finders

\begin{tabular}{|c|c|}
\hline Structural parameter & $\begin{array}{l}\text { Structural } \\
\text { dimensions }\end{array}$ \\
\hline Hydrocyclone diameter $\mathrm{D}, \mathrm{mm}$ & 50 \\
\hline Inner vortex finder diameter $\mathrm{d}_{01}, \mathrm{~mm}$ & 6 \\
\hline Outer vortex finder diameter $\mathrm{d}_{\mathrm{o} 2}, \mathrm{~mm}$ & 20 \\
\hline Underflow port diameter $\mathrm{d}_{u}, \mathrm{~mm}$ & 6 \\
\hline $\begin{array}{l}\text { Feed inlet equivalent diameter } \mathrm{d}_{\mathrm{i}}, \\
\mathrm{mm}\end{array}$ & 12 \\
\hline $\begin{array}{c}\text { Outer overflow pipe insertion depth } \\
\mathrm{H} 4, \mathrm{~mm}\end{array}$ & 85 \\
\hline $\begin{array}{l}\text { Inner overflow pipe insertion depth } \\
\mathrm{H} 6, \mathrm{~mm}\end{array}$ & $\begin{array}{c}65,75,85 \\
95,105\end{array}$ \\
\hline $\begin{array}{l}\text { Thickness of the overflow pipe s1, s2, } \\
\text { mm }\end{array}$ & $2,2.5$ \\
\hline $\begin{array}{l}\text { Extension length of the overflow pipe } \\
\mathrm{H} 5, \mathrm{~mm}\end{array}$ & 28 \\
\hline Cylinder height $\mathrm{H} 1, \mathrm{~mm}$ & 116 \\
\hline total height $\mathrm{H} 2, \mathrm{~mm}$ & 310 \\
\hline Underflow pipe height H3 (mm) & 15 \\
\hline
\end{tabular}

\section{Model building of the flow field within the cyclone}

The schematic of the cyclone separator with two overflow pipes is shown in Figure 1. The Flow field of cyclone with double vortex finders is shown in Figure 2 with and its structural parameters are described in Table 1. Figure 3 illustrates the meshed structure by the ICEM software. Set the entrance as the velocity entrance and both the overflow and underflow as pressure exits. Except there is a residual pressure at the external overflow outlet, both the internal overflow pipe and the underflow pipe are in contact with the air. The pressure-veloc- 


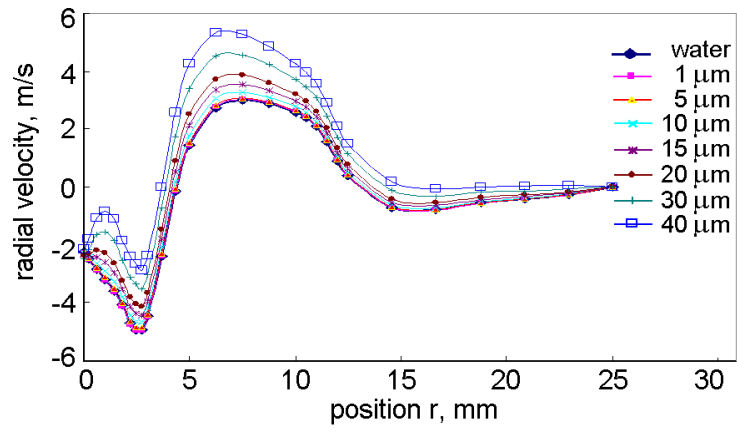

Fig. 4 The following performance between particle diameter and fluid medium along the radial direction

ity coupling SIMPLE method is adopted to calculate the control parameters. PRESTO is employed for pressure discretion scheme; Quick method for the momentum discretion; the rest use the first-order upwind scheme. The residual error is set to be $10^{-4}$ and steady state calculation is adopted. For multi-phase, the Mixture model is adopted.

\section{Investigation of the following per- formance between the solid particles and the liquid medium}

\subsection{Effect of the particle size on follow- ing performance}

Seven $\mathrm{CaCO}_{3}$ particle sizes- 1, 5, 10, 15, 20 30 and $40 \mu \mathrm{m}$ were chosen with a volume percentage of $0.3 \%, 0.5 \%, 0.7 \%, 0.7 \%, 0.5 \%, 0.5 \%$, $0.3 \%$, respectively. The total volume percentage of the particles amounts to $3.5 \%$. Both the particle and water velocity entering the cyclone separator are assumed to be $5 \mathrm{~m} / \mathrm{s}$. By numerical simulations, we obtained the effect of each particle size on the behavior of relative motion between water and $\mathrm{CaCO}_{3}$ in the radial, axial and tangent directions.

For the interest of correlating the relative motion with the particle size, the simulation results at the section at $z=170 \mathrm{~mm}$ for the above 7 different particle sizes are all shown in Figure 4. As can be seen, the larger the particle size, the larger the difference of the sliding speed in the radial direction between the solid particles and the liquid medium indicating an easier separating process for the larger particles. Furthermore, the radial velocity of both the particles and the liquid experienced from negative to the positive, which indicates the particles reversed the moving direction. The smaller particles is moving in the same direction as the liquid medium-both from the wall directing to the axis; while for larger particles, they first moved in the same direction of the

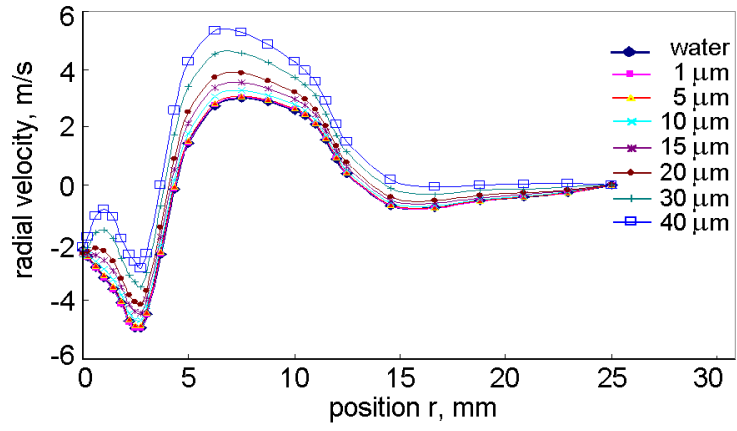

Fig. 5 The following performance between particle diameter and fluid medium along the axial direction

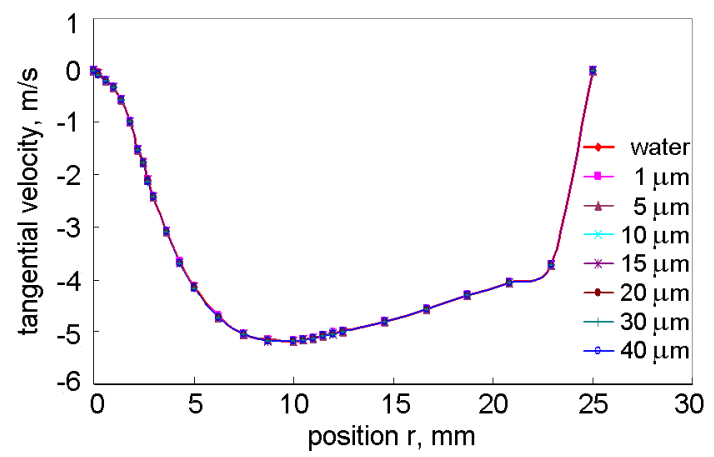

Fig. 6 The following performance between particle diameter and fluid medium along the tangential direction

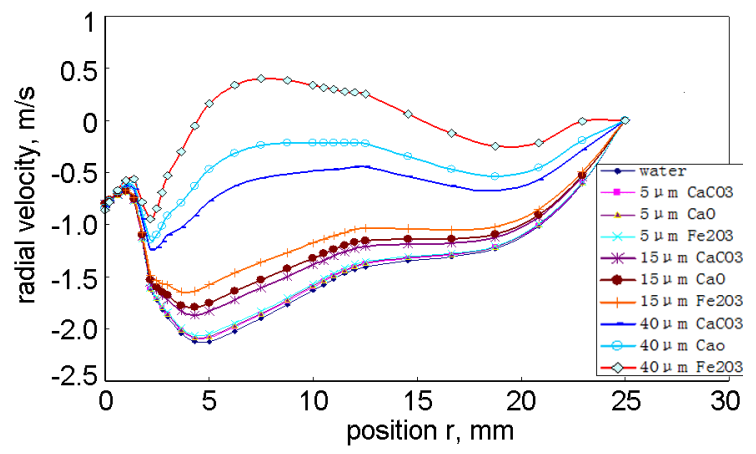

Fig.7 The following performance between particle density and fluid medium along the radial direction

liquid medium but then changed the direction moving from the axis to the wall.

Figures 5 and 6 demonstrate the effect of the particle size on the relative motion between two phases in both the axial and tangent directions. As can be seen, regardless of the particle size, $1 \mu \mathrm{m}$ or $40 \mu \mathrm{m}$, the sliding speed of the particles and the liquid medium is almost the same indicating independence of the relative motion on the particle size. In addition, the independence is not altered by changing the radius of the cyclone separator. These results show that the 


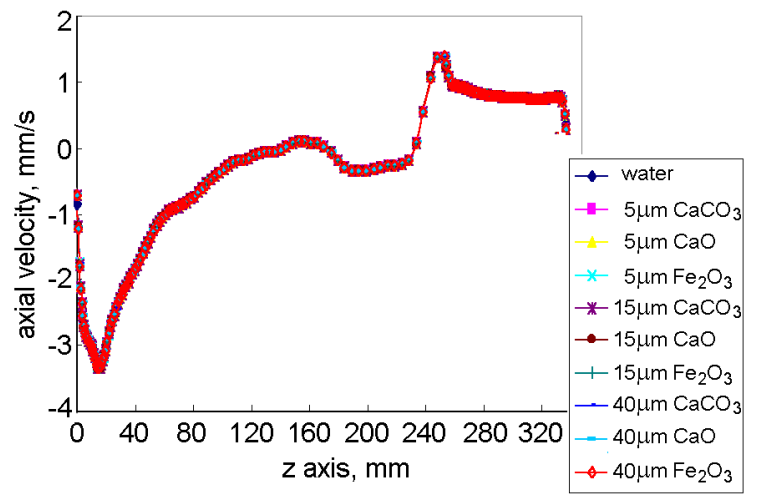

Fig. 8. The following performance between particle density and fluid medium along the axial direction

particles are well synchronized with the liquid medium in the radial and tangent directions.

\subsubsection{The effect of the density on the relative motion}

Three particles with different densities are selected to investigate its correlation with the relative motion. They are $\mathrm{CaCO}_{3}, \mathrm{CaO}$ and $\mathrm{Fe}_{2} \mathrm{O}_{3}$ with a density of $2800 \mathrm{~kg} / \mathrm{m}^{3}, 3320 \mathrm{~kg} / \mathrm{m}^{3}$ and $4500 \mathrm{~kg} / \mathrm{m}^{3}$, respectively. The size for each component is $5 \mu \mathrm{m}, 15 \mu \mathrm{m}, 40 \mu \mathrm{m}$ and the volume percentage is $0.5 \%, 0.7 \%$ and $0.3 \%$. With initial and boundary conditions unchanged, the dependence of the relative motion on the particle density is determined using the numerical simulation.

Figure 7 shows the correlation between the particle size and the relative motion between two phases in the radial direction. As can be seen, the larger the particle density, the larger the difference of the sliding speed between two phases. This indicates that at the same radial position, the larger the density, the easier the separation assuming the particle size is the same. It is also worth mentioning that the position in the radial direction can affect the degree of relative motion - the closer to the wall, the lesser degree of the relative motion.

Figures 8 and 9 show the correlation between the particle density and relative motion in both the axial and tangent directions. As can be seen, the sliding speed of the particles and the liquid medium is almost the same in both directions. This indicates the relative motion is independent of the particle density. In addition, this independence is not altered by the radius of the cyclone separator.

\subsubsection{The effect of the particles' con- centration on the particles and the liquid medium}

The $\mathrm{CaCO}_{3}$ is used again to find out the concentration effect on the following performance between the particles and liquid. The radial, axial and tangent velocity are calculated for two concentrations $3.5 \%$ and $10.5 \%$ (volume

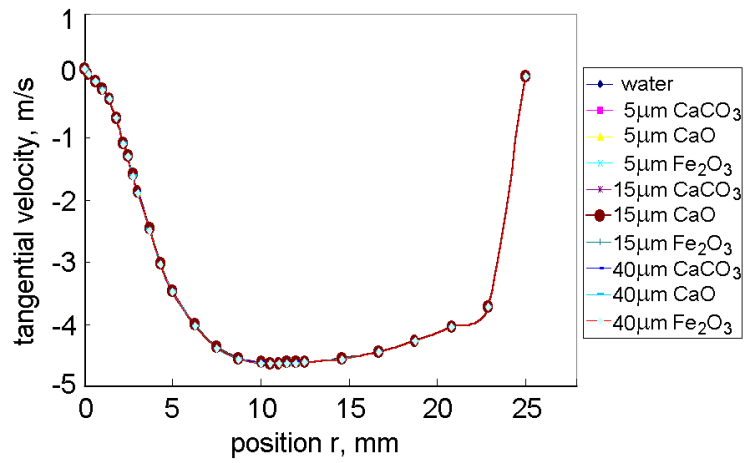

Fig. 9 The following performance between particle density and fluid medium along the tangential direction

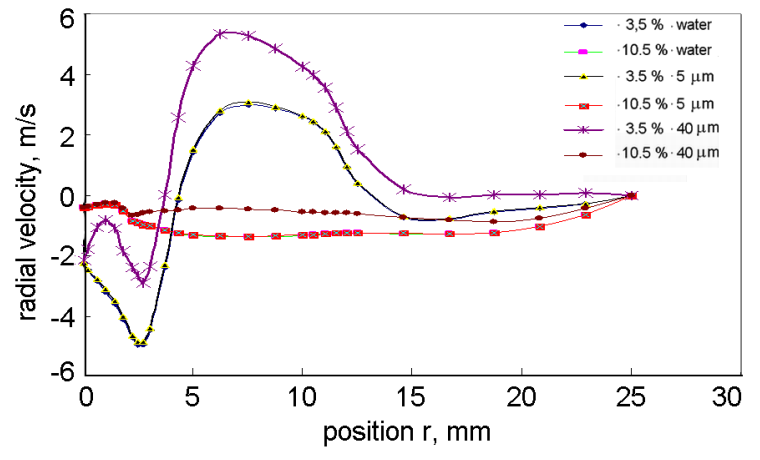

Fig. 10 The following performance between particle concentration and fluid medium along the radial direction

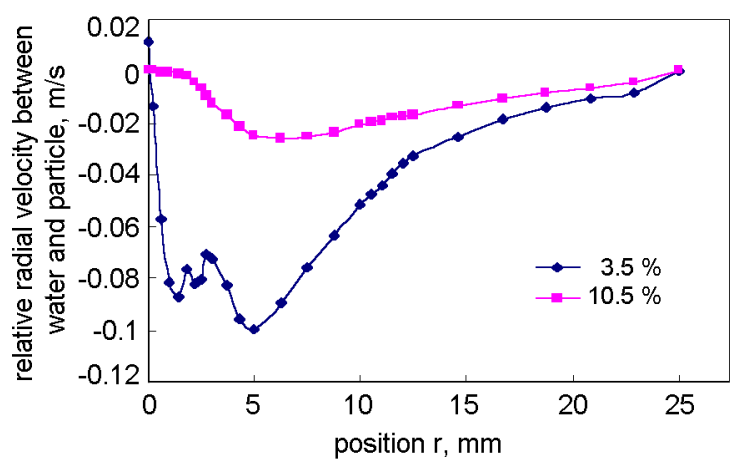

Fig. 11 The following performance between concentration and fluid medium with $5 \mu \mathrm{m}$ particle diameter along the radial direction

percentage), each concentration with two different particle sizes $5 \mu \mathrm{m}$ and $40 \mu \mathrm{m}$. With the initial and boundary conditions maintained, the numerical simulation gives the results on how the following performance changes with the concentration. For comparison, two results (one for each concentration) are put together, as shown in Figure 10, to demonstrate the dependence of following performance on the concentration of particles in the radial direction. As can be seen from Figure 10, for the particle size at $40 \mu \mathrm{m}$, the following performance increases as the concentration increases indicating that 


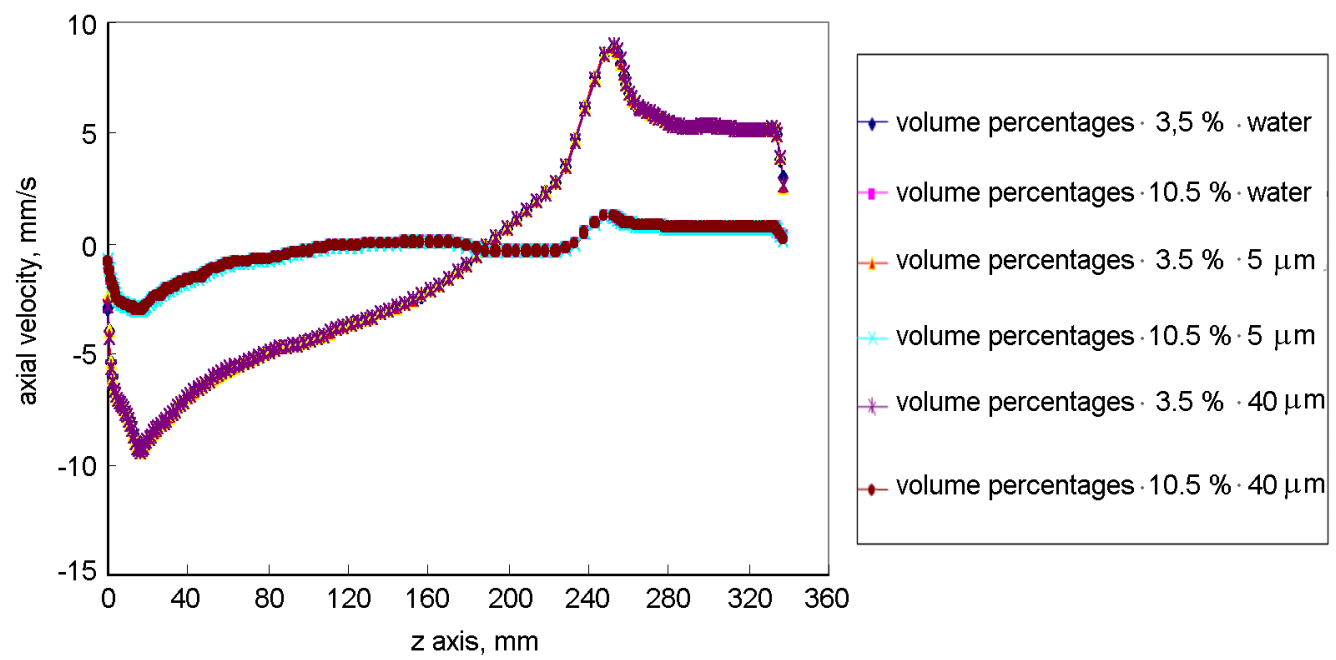

Fig. 12 The following performance between concentration and fluid medium along the axial direction

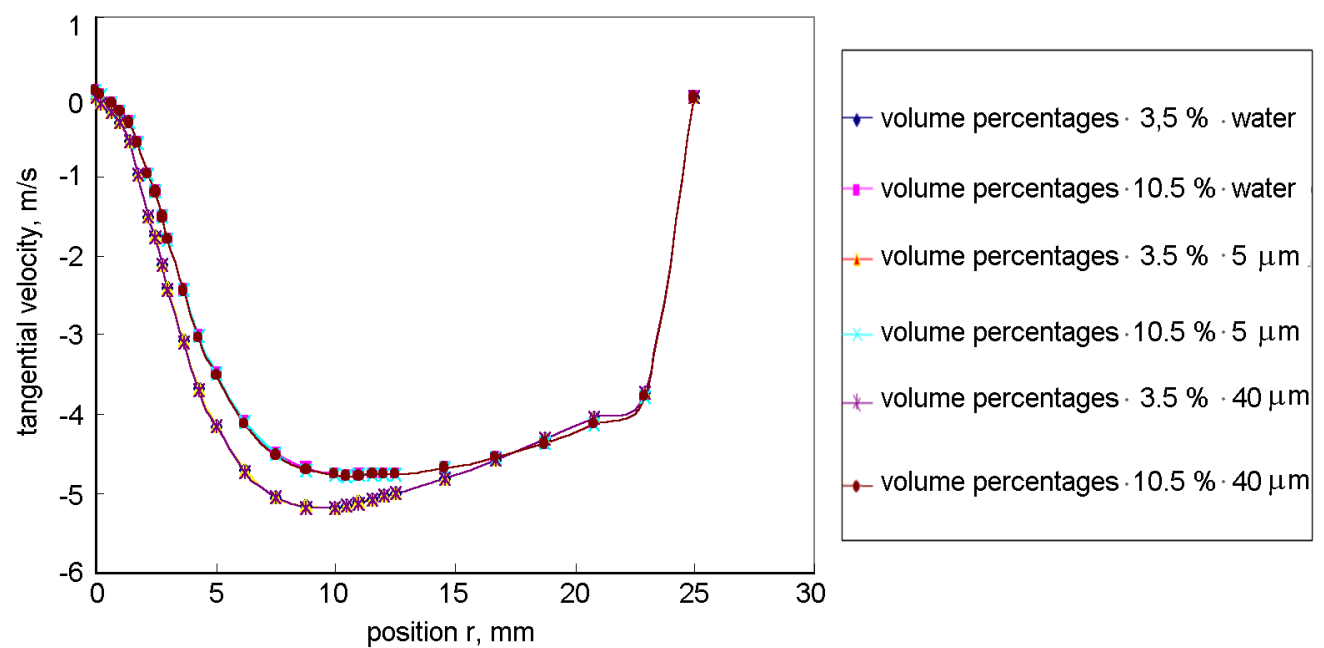

Fig. 13. The following performance between concentration and fluid medium along the tangential direction

it becomes increasingly harder to separate the particles from the liquid medium as the volume percentage raising.

For the particle size at $5 \mu \mathrm{m}$ with both volume percentages (i.e., $3.5 \%$ and $10.5 \%$ ), there is a difference in the sliding speed in the radial direction. However, the difference is extremely small indicating the following performance is better at the particle size of $5 \mu \mathrm{m}$ than that at $40 \mu \mathrm{m}$ for both concentrations. Meanwhile, when the particle size is $5 \mu \mathrm{m}$, the following performance at both concentrations doesn't show a discernible difference. To compare more accurately, we use the radius of the cyclone separator as X-axis, and place the difference of the sliding speed between two phases for both concentrations on one graph, as illustrated in Figure 11. It now becomes apparent that the following performance is affected by the concentration indicating that as the concentration increases, the following performance increases too even when the particle size is small. It is also worth noting that the position along the radial direction can affect the following performance. It becomes better as the cyclone radius decreases and becomes better as the position is closer to the wall.

Figures 12 and 13 show the following performance as a function of the concentration in other two directions the radial and the tangent. As can be seen, the sliding speed of the particles and the liquid medium is almost the same in both directions indicating the relative speed between the particles and the liquid medium is zero. The particles and the liquid medium basically stick and flow together, and the following performance is independent of the particles' size and the radial position. 


\section{Conclusions}

Utilizing the theory of fluid dynamics and multi-phase turbulence model, we have established a mathematical model for two phase (solid particles and the liquid medium) within a cyclone separator with two overflow pipes and investigated the effect of particle size, density and concentration of particle on the relative motion between two phases.

(1) In the axial and tangent direction, the relative sliding speed is almost zero and is independent of the particle size, density and concentration along the cyclone separator radius.

(2) In the radial direction, the study indicates unfavorable following behavior for the larger particles, higher density particles, and lower slurry concentration by analyzing the following behavior of the solid particles with the liquid flow. This is more favorable for the separation of particles from the liquid flow.

(3) The radial position can affect the relative motion regardless of the particle size, density and slurry concentration. In general, the effect of radial distance on the following behavior shows that following behavior is better while closer to the wall of the hydrocyclone.

\section{Acknowledgements}

This work is supported by the National Natural Science Foundation of China (No.21276145) and the Natural Science Foundation of Shandong province (ZR2016EEM37) and guideline plan project for scientific and technological research of China National Coal Association (No. MTKJ2016-280)

\section{References}

1. D. Bradely. The Hydrocyclone. London: Pergamon Press, 1965.

2. L.Svarovsky. Hydrocyclones. Holt, Rinchart and Winston, London, 1984.

3. Dueck J., Matvienko O., Neesse T. Theor Found Chem Engin, 34, 428, 2006.

4. Xu jirun, Luo xi. Flow field theory of the hydrocyclone. Beijing, Sciences Press. 1998.

5. M. G. Driessen. Rev Indust Mining[. Special Issue 1951, 4, 449, 1951.

6. E. Criner. In Proceedings of Int. Conf. on Coal Preparation, 1950.

7. K. Rietema. Performance and Design of Hydrocyclones, Eng. Sci 15, 298, 1961.

8. A. R. Houand-Batt. A Bulk, Inst Mining Metall, 3, C21, 1982.

9. P.H.Fahlstrom. Studies of the Hydrocyclone as a Classifier. Proc. 6th, Int.Miner. Process. Congr., Cannes, 1963, 87-109.

10. H. Schubert and T. Neesse. In Proc. of 1st Int. Conf. on Hydrocyclones. BHRA, Cambridge, England, 1980. 